\title{
SUSTAINABLE MOBILITY IN VALPARAÍSO, CHILE, AND ITS RELATIONSHIP WITH TOPOGRAPHY AND SOCIO-SPATIAL CONDITIONS
}

\author{
VICENTE APRIGLIANO FERNANDES* AND HERMANN MANRÍQUEZ TIRADO
}

Instituto de Geografia, Pontificia Universidad Católica de Valparaíso, Valparaíso, Chile.

*Corresponding author: vicente.aprigliano@pucv.cl

Submitted final draft: 24 September $2020 \quad$ Accepted: 5 February $2021 \quad$ http://doi.org/10.46754/jssm.2021.10.010

\begin{abstract}
Valparaíso presents complex topographical and socio-spatial conditions, which lead one to question, at first sight, which factors may be the determinant for promoting sustainable urban mobility. This study aims to respond to this question by testing two hypotheses, one that is related to the neo-environmental determinism and another to the social production of urban space. For the testing of these hypotheses, this study proposes a sustainable mobility score as the dependent variable, considering one indicator for each sustainable dimension (social, environmental and economic), a topographic indicator as an independent variable and a socio-spatial indicator as another independent variable. With these values, this study undertakes two separate linear regression models to identify the relationship between the human-induced environmental changes and socio-economic conditions with the sustainable mobility score of the survey zones in Valparaíso. The results show that the expected scores for sustainable mobility do not relate positively with favourable topographic conditions for sustainable mobility and that socio-economic conditions have a negative relationship with the sustainable mobility score.
\end{abstract}

Keywords: Urban mobility; neo-determinism; sustainability.

\section{Introduction}

Sustainable mobility has been declared by the United Nations (2016) as a global, national, and local goal. There are good examples of cities that have achieved this goal, such as Strasbourg (France) and of others, such as Lyon (France), which are showing tendencies (transitions) towards achieving this goal through transitoriented developments of extensive geographical reach and a variety of public transport., Utrecht (Netherlands), meanwhile, has constructed the world's largest underground bicycle parking garage (Guikink, 2019).

Technology can be a breaking point for sustainable mobility. Nevertheless, the physical (topographical) and socio-spatial conditions are important aspects that can favour or hamper a sustainable transition, especially in cities of the global south that are still in an initial transition phase towards "sustainable" development. This is the case in the port city of Valparaíso. A significant part of its population lives on steep hills and in houses along narrow streets (Subsecretaría de Transporte, 2014). Even in
Rio de Janeiro, in Brazil, more than $20 \%$ of the population lives in favelas (IBGE, 2010) in a complex physical and human geographic setting.

Athough there are studies related to urban mobility in Valparaíso (Álvarez et al., 2009; Caro \& Aránguiz, 2012; Olivi et al., 2016; Urquieta, 2018), none of them have explored deeply enough the geographical patterns related to the development of sustainable mobility. This study fills a small part of this gap in the exploration of sustainable mobility by geographical analysis of the city of Valparaíso in Chile. It is essential to highlight that a specific historic quarter of Valparaíso was declared part of the World Cultural Heritage by UNESCO in 2003 (UNESCO, 2003), pointing out the relevance of this part of the world as a case study for the academic community.

Spatial mobility is a determining factor for the functioning of a human or urban agglomeration because of its essential role in connecting people to places (Coe et al., 2007). However, mountainous cities commonly present complex topographic and geomorphological conditions, 
which may affect citizens' behavioural patterns in the use of the urban space, and can also impact the way a city expands. Naturally, this context leads to a long but not worn out discussion related to environmental determinism. In the past few years, environmental determinism has re-emerged as neo-environmental determinism (Judkins et al., 2008; Meyer \& Guss, 2017). According to Meyer and Guss (2017), the definition of environmental determinism is, "... either of treating the environment as a factor that has an influence of a certain character regardless of the kind of society it acts upon, or of placing chief or sole emphasis on the environmental elements in a situation at the expense of social ones." (2017, p. 41).

The definition of neo-environmental determinism takes both approaches in the previous citation. However, it emphasises the second approach, which considers that humaninduced environmental changes have an impact on modern society (Judkins et al., 2008; Meyer \& Guss, 2017).

On the other hand, there is the social perspective of the production of urban space, which regards it as a product of an economic construct of space (based on production, consumption, exchange, and management), spatial expression of political-institutional aspects of society and the nature of social contradiction (Castells, 2009). The production of urban space, from this perspective, is related to the spatial forms whose persistence is induced by previous social structure and through different actions of individuals or social groups (Fernandes, 2017).

Valparaíso has suffered human-induced environmental changes since the mid-19th century with an artificial expansion of the coastal area with materials (sand and soil) brought from nearby hills to the coast to occupy what once was the sea (Sánchez et al., 2009). Also, the city of Valparaíso is in a seismically active zone and has intermittently experienced massive earthquakes that caused many topographical changes even after the first artificial expansion of the city.
It is relevant to highlight that a human or urban agglomeration is dependent on the movement of people and goods between places with different meanings and functions (Corrêa, 1995). Therefore, spatial mobility of the people represents physical consumption and occupation of space, that under, a neo-environmental determinism approach, human-induced changes of the environment should affect the way people move in a particular territory. On the other hand, Valparaíso is located in the Region of Valparaíso, which presents a complex socio-spatial setting as a result of income inequality and residential segregation (Athens \& Ormeño, 2010; Borsdorf $\&$ Hidalgo, 2008). Therefore, this context may have a significant effect on individual behaviour towards mobility (Zegras \& Srinivasan, 2007).

Also, since the 1970 s, there is a rising interest in sustainable development on a global scale to maintain or improve the present conditions without compromising the possibilities of future generations to meet their own needs (Brundland, 1987). This goal involves the preservation of natural resources for future generations. Furthermore, it is evidence of commitment to developing economic and social equity (Paniagua \& Moyano, 1998). Nowadays, sustainable interest has been widely adopted by several countries by committing to the Sustainable Development Goals (SDGs) declared by the United Nations (2017). SDG 11 refers to concerns over developing sustainable mobility. Building cities that are inclusive, safe, resilient, and sustainable pose major challenges for developing countries (Henríquez et al., 2006; UNDP, 2018).

The types of impacts of urban mobility in terms of sustainability can be related to environmental, social, or economic conditions. Environmental impacts are related to greenhouse gas emissions (GHG), air pollution, noise pollution, and land-use changes (Rodrigue et al., 2013; Zegras, 2004). The social perspective raises concerns over equitable access to a variety of activities in the city and the impacts of unsustainable transportation modes on the health of citizens (Bourne, 1976; Hanson \& 
Giuliano, 2004; Litman, 2007; Rojas et al., 2016). The economic concerns are related to the affordability of transportation in terms of monetary cost and travel time for people of various social classes (Cervero et al., 2009; Fernandes, 2017; Litman, 2007; Ureta, 2008). Therefore, with the understanding of the impacts that various mobility contexts can have on cities and understanding of the concept of sustainability, sustainable mobility can be conceptualised as a pattern of mobility that preserves the current social, environmental, and economic conditions for the present generation without affecting future generations. In other words, preserving inter- and intra-generational conditions of living and moving. However, cities should consider geographical obstacles in terms of topography and feasibility of overcoming space and complex socio-spatial conditions prevalent in urban environments.

Based on the neo-environmental determinism approach, environmental conditions may affect urban mobility positively or negatively in terms of attaining more sustainable behaviours. Understanding that Valparaíso has undergone human-induced environmental changes, the neo-environmental determinism approach would assume that these changes have been the determinants of social condition and behaviour. However, studies have shown that steeper slopes are commonly considered as an unfavourable condition for non-motorised modes of mobility (for example, walking and cycling) (Beheshtitabar et al., 2014; Lin \& Chang, 2010; Su et al., 2010).

Another perspective asserts that the mobility patterns are conditioned by a socially constructed space created by social contradictions and interests. Some studies that took this approach have shown that higher levels of income are usually related to higher levels of car ownership and use (Dargay, 2001; Dargay \& Vythoulkas, 1999; Vasconcellos, 2014).

Taking these perspectives into consideration, this paper aims to analyse whether sustainable mobility behaviour in Valparaíso is related to topographic and/or to socio-spatial conditions.
Under the discussed issues, the following two hypotheses are proposed to be tested:

- H1: Steeper slopes are considered unfavorable conditions for sustainable mobility, such as non-motorised mobility (walking and cycling). Therefore, in other words, lower gradients (gentler slopes) should be favorable for more sustainable mobility patterns, while steeper slopes have the opposite effect of generating adverse conditions for sustainable mobility.

- H2: Higher-income should be related to higher use of private transportation modes, while citizens with lower-income would tend to adopt more sustainable mobility patterns because they cannot financially afford to acquire any mode of private transportation.

The proposed method to evaluate the objective of this paper is a linear regression model with indicators suggested in the next section (materials and methods), which represent sustainable mobility, topography, and socio-spatial conditions. Furthermore, this study focuses on proposing an analytical process that could be replicated by academics and professionals in different fields, with varying levels of reliability for quantitative analysis.

\section{Study Area}

This section contextualises the study area through urban mobility, topography, and sociospatial conditions based on the variables that have been presented in the previous section. It is essential to highlight that although the study area is the municipality of Valparaíso, the trips or residents of certain areas are not considered in this study and they are presented as "no-data" areas. Therefore, even for the slope data, which is available for the entire study area, it is displayed and considered only for the surveyed zones that have available data related to both socio-spatial conditions and urban mobility. Furthermore, the variables presented here are spread over five levels through the natural break's method of Jenks (1967). 
Valparaíso, with approximately 300,000 residents, is the second-most populous municipality of Gran Valparaíso (Subsecretaría de Transporte, 2014). Figure 1 shows the average slope and income in each survey zone. From the slope data, it may be observed that the northern part, which is the Pacific coast, has a green area that represents the plain of Valparaíso, where most of the economic activities of the city are concentrated (Sánchez et al., 2009). One could say it is an equivalent of a Central Business District (CBD). In the southern part of the municipality, there is also an area with gentler slopes, and is characterised by its low service/ commercial and residential density. The survey zones near the plain of Valparaíso are known as the "cerros" (hills) of the city, where most people live (Sánchez et al., 2009). Therefore, it is relevant to assume that most of the citizens of Valparaíso have to traverse steep slopes of the city.

Figure 1 shows that residents with low income live on the fringes of Valparaíso, while those with higher income live near or in the plain area of the city.
Figure 2 shows the $\mathrm{CO}_{2}$ emission by private transportation per capita and the portion of walking and cycling trips with at least 15 minutes of duration in all trips by all modes in Valparaíso. Regarding $\mathrm{CO}_{2}$ emissions per capita by private transportation modes, the areas with higher emission are located in and around the plain area of Valparaíso, while other parts of the municipality show lower levels of emission per capita. This is the result of the concentration of the trips by private transportation to and from the CBD located in the plain areas and the surrounding hills at the beginning and the end of the day.

From the proportion of walking or cycling trips of at least 15 minutes in all trips in each survey zone, it may be observed that most of the areas with higher walking or cycling trips are located in the hills of the urban agglomeration in Valparaíso, while the plain areas show a smaller portion of walking and cycling trips of at least 15 minutes.

Figure 3 shows the average commute time in every survey zone in Valparaíso. Only the data of trips based on a survey of the origin and

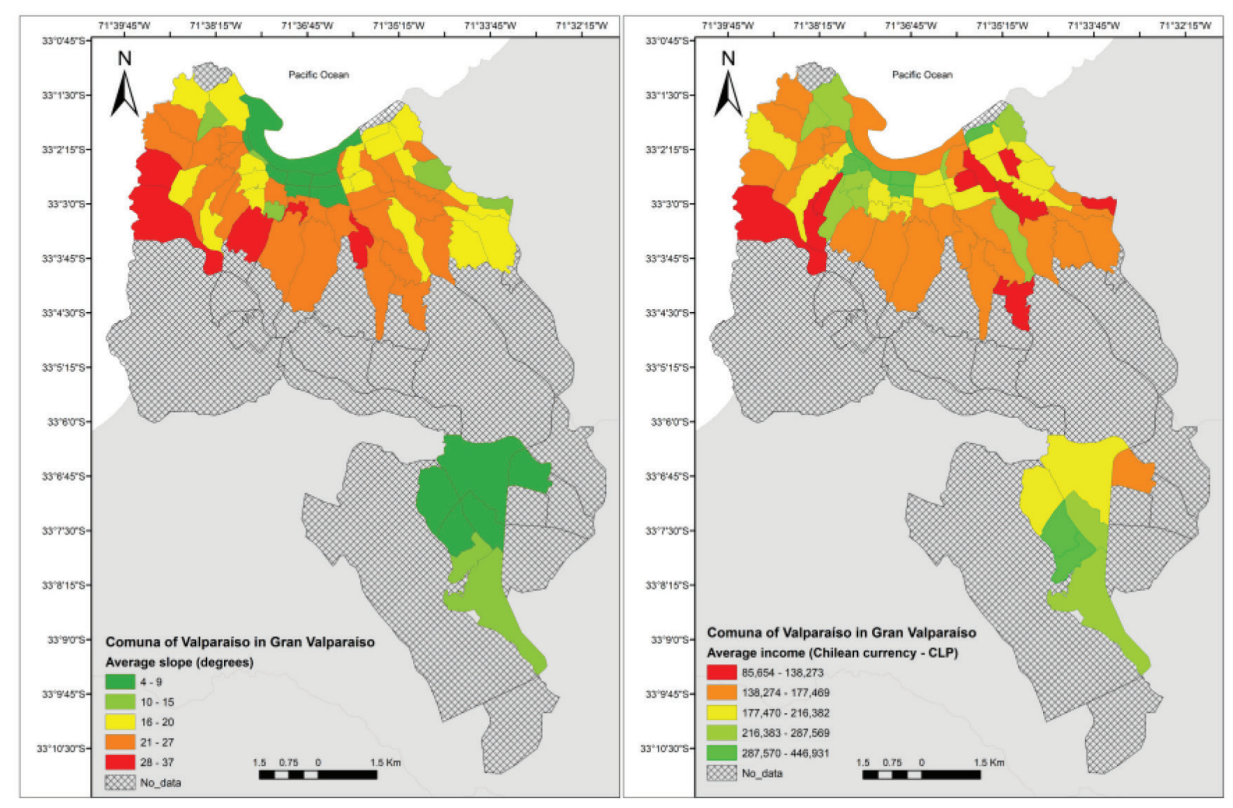

Figure 1: Average slope and income by survey zone in the municipality of Valparaíso 
destination within the municipality of Valparaíso are considered in this study (Subsecretaría de Transporte, 2014). Figure 3 shows that the areas with the worst average travel time are in or near the plain of Valparaíso, and best travel times are presented in the hills.
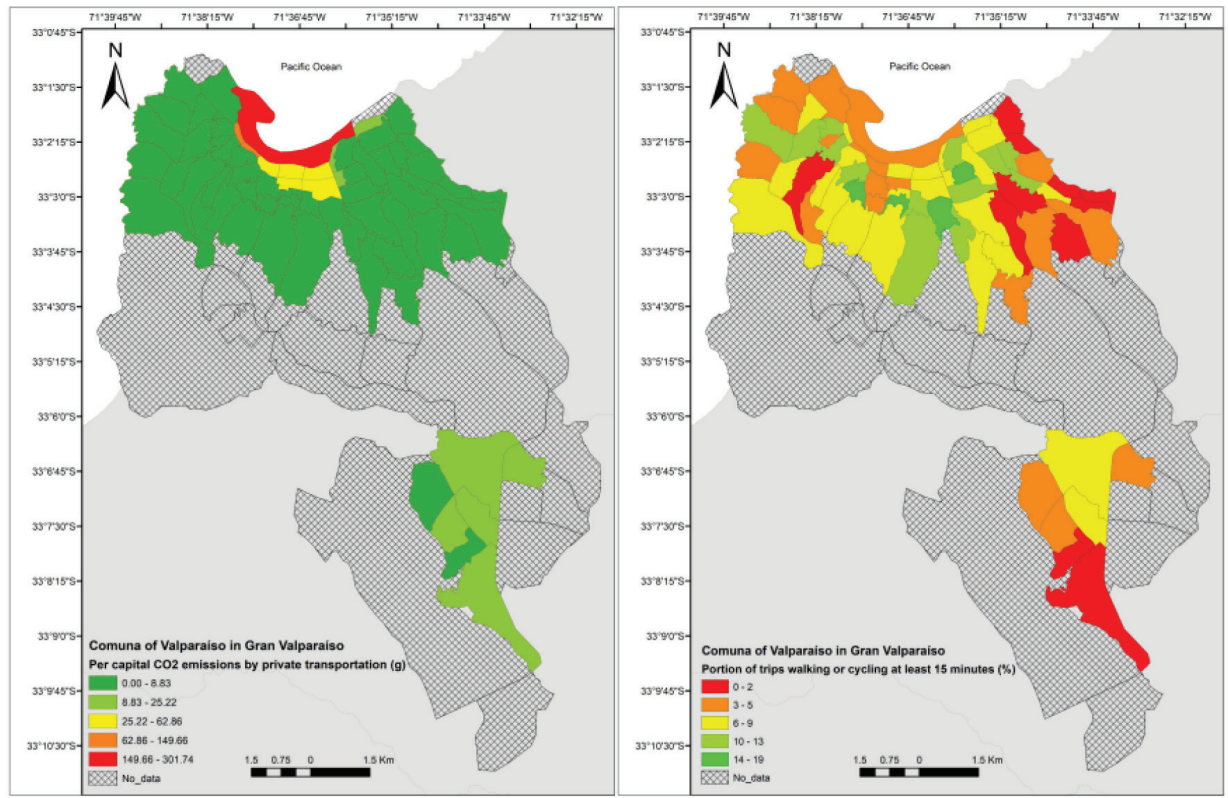

Figure 2: Per capita $\mathrm{CO}_{2}$ emissions by private transportation and the portion of walking and cycling trips with at least 15 minutes of duration by each survey zone as origin trip

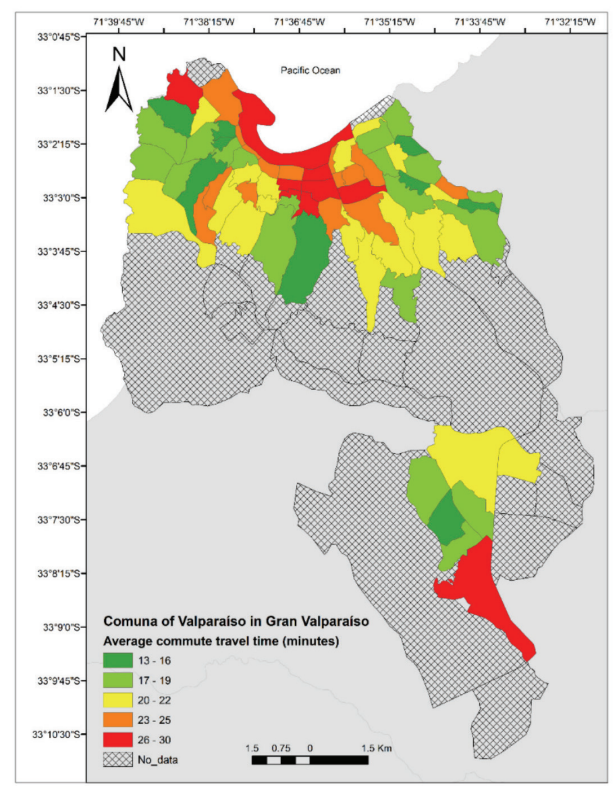

Figure 3: Average commute travel time by survey zone as origin trips 
The above-described variables indicate that areas of Valparaíso with steeper slopes have less $\mathrm{CO}_{2}$ emission per capita (by private transportation), a higher number of walking and cycling trips of at least 15 minutes, and trips that are shorter in terms of time spent. The zone of the city of Valparaíso where residents with higher income live is near or within areas with higher $\mathrm{CO}_{2}$ emission, fewer walking, and cycling trips, and have longer average travel time.

\section{Materials and Methods}

The proposed method involves the use of the linear regression model (Rogerson, 2012) for two purposes. The first purpose is to correlate the sustainable mobility score with the normalised values of the slopes. The second purpose is to correlate the sustainable mobility score with normalised values of socio-spatial conditions (based on average income). The first regression intends to test the neo-determinist approach and the second to test the social approach.

The method for normalisation of value is presented in equation 1 and the variables used in this study are presented in Table 1. In addition, regarding the data related to the survey of the origin and destination of trips, this study focuses on data related to working days (from Monday to Friday) and trips that are within the municipal limits of Valparaíso.

For methodological reasons, it is important to highlight that the study area is a part of the comuna (equivalent to municipality) of Valparaíso, which is within the metropolitan area of Valparaíso (also called Gran Valparaíso) (see Figure 4). This is also the geographical settings of the available data offered by Subsecretaria de Transporte (2014). Furthermore, the focus is on trips within the study area. Therefore, data related to trips to or from outside the study area are excluded from this analysis.

Table 1: Variables for sustainable mobility, topographic and socio-spatial conditions

\begin{tabular}{llll}
\hline \multicolumn{1}{c}{ Type of Data } & \multicolumn{1}{c}{ Variables } & \multicolumn{1}{c}{ Description } & \multicolumn{1}{c}{ Source of Data } \\
\hline & Social (S) & $\begin{array}{l}\text { The portion of people who walk or } \\
\text { bicycle sufficiently for health }(>=15 \\
\text { minutes) in comparison with total } \\
\text { trips }\end{array}$ & $\begin{array}{l}\text { EOD of Gran } \\
\text { Valparaíso } \\
\text { (Subsecretaría de } \\
\text { Transporte, 2014) }\end{array}$ \\
\cline { 2 - 4 } & & & EOD of Gran \\
Sustainable & Environmental (Env) & $\begin{array}{l}\text { Per capita CO2 emissions by private } \\
\text { transportation (g) }\end{array}$ & $\begin{array}{l}\text { Valparaiso } \\
\text { (Subsecretaría de }\end{array}$ \\
& & Transporte, 2014) and \\
& & GFEI (2018)
\end{tabular}




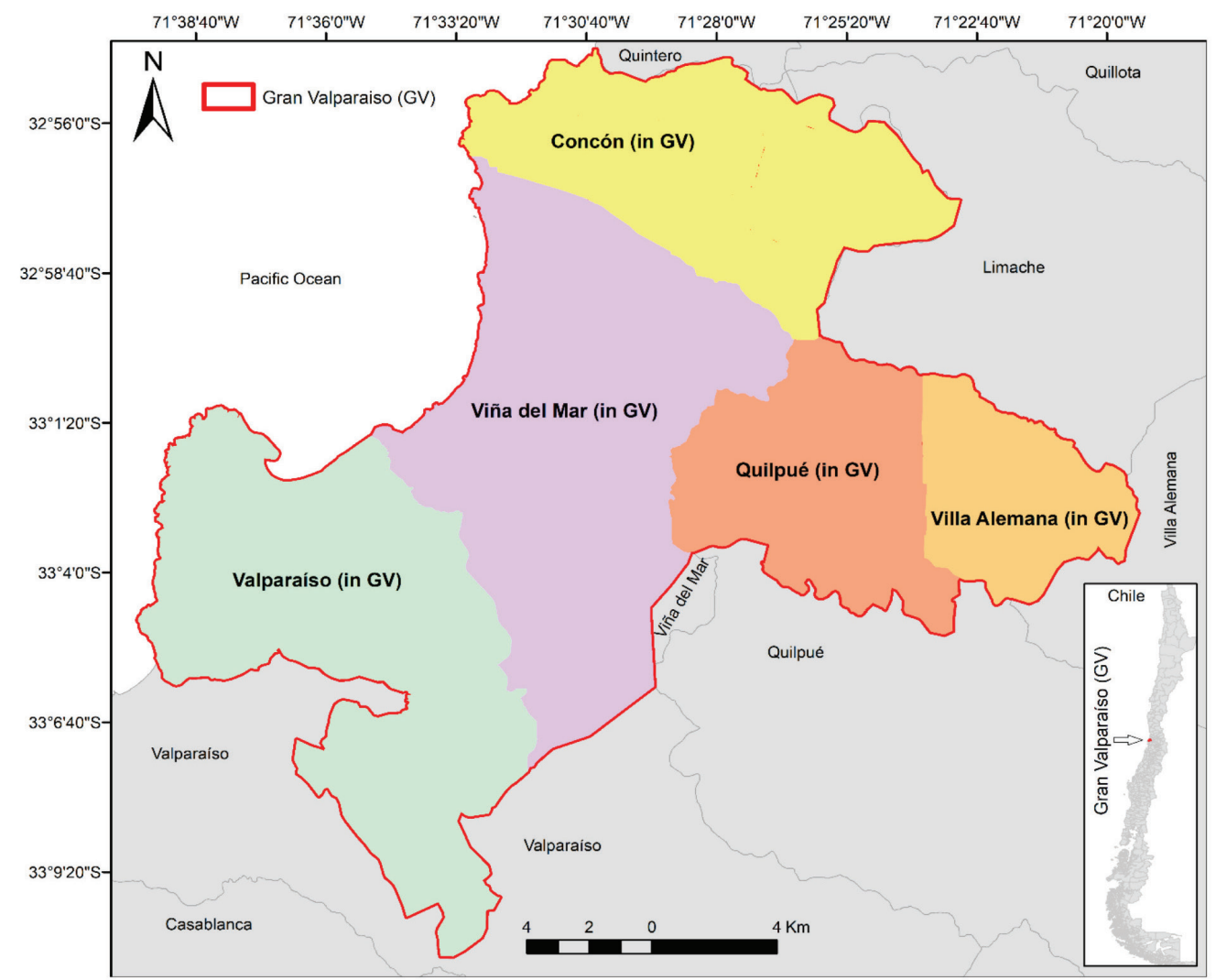

Figure 4: Gran Valparaíso, Chile

$N i j=\frac{X i j-X i m i n}{X i m a x-X i m i n}$

(1)

\section{Where:}

Nij: Normalised values of variable i (social, environmental, economic, slope or socio-spatial conditions) for a survey zone $\mathrm{j}$

Xij: refers to the group of variables $\mathrm{i}$ in a certain survey zone $\mathrm{j}$

Ximin: The minimum value of the group of values of variable $i$

Ximax: The maximum value of the group of values of variable $i$

In the case of the variables related to the environment, economy, and slope, equation 1 is reversed (by taking one minus Nij), where
1 represents the best conditions and zero the worst conditions. Furthermore, it is relevant to highlight that the calculation of emissions is based on the minimum distance from the centroid to the centroid in each survey zone of the EOD of Gran Valparaíso of 2014, using the streets as reference. The distance information was collected with Google API (of Google Maps), and this data is applied to the origin and destinations of each trip of the EOD of Gran Valparaíso of 2014. Also, the factor of $\mathrm{CO}_{2}$ emissions, which is $175 \mathrm{CO}_{2} \mathrm{~g} / \mathrm{km}(\mathrm{EF})$ for lightduty vehicles, is considered as the benchmark for Chile in a study by GFEI (2018). The substitution of the respective values in equation 2 gives the values of $\mathrm{CO}_{2}$ emission per trip.

$$
\mathrm{CO}_{2} \text { emission for each trip }(\mathrm{g})=\text { Distance }(\mathrm{km}) * \mathrm{EF}(\mathrm{g} / \mathrm{km})
$$


The sustainable mobility score (equation 3) that is used as a dependent variable in both linear regressions in this study is based on the sum of the normalised values of the sustainable mobility indicators (social, environmental and economic).

$$
S M S j=N s j+N e n v j+N e c o n j
$$

Where:

SMSj: Sustainable mobility score in the survey zone $\mathrm{j}$

Nsj: $\quad$ Normalised value of the social variable in the survey zone $\mathrm{j}$

Nenvj: Normalised value of the environmental variable in the survey zone $\mathrm{j}$

Neconj: Normalised value of the economic variable in the survey zone $\mathrm{j}$

After collecting data and processing it with equations 1,2 , and 3 , the next step is to generate two linear regression models, both of which will have the sustainable mobility score as a dependent variable. What differentiates the two is that one has the normalised slope as the independent variable and the other has the sociospatial condition as the independent variable. Therefore, one test takes a neo-deterministic approach, and the other tests the social approach on the production of urban space. The relevant information of the regression considered in this are the p-values and the coefficient values, which are used to confirm or reject the proposed hypotheses and to identify the level of influence of the independent variables on sustainable mobility. The specific conditions to accept, reject or discard the hypotheses proprosed in the introductory section (H1 and $\mathrm{H} 2$ ) are presented in Table 2.
The null hypothesis is based on the assumption that the independent variable does not have any correlation with the dependent variable. On the other hand, if the p-value is lower than or equal to 0.05 (a condition also referred as alternative hypotheses) means that there is a higher probability of correlation between the independent and dependent variables, leading to the possibility to accept or reject the hypotheses proposed in the introductory section of this article. The neo-deterministic approach (H1) is used to understand the influence of topography (an independent variable) on sustainable mobility (a dependent variable). The sociospatial approach (H2) is related to the influence of average income (an independent variable) on sustainable mobility. Moreover, besides the testing of hypotheses, this study also undertakes a descriptive analysis of the variables and the relationship between them from a spatial perspective.

\section{Results and Discussion}

Figure 5 shows the sustainable mobility score by survey zone in Valparaíso. Also, this figure presents two images of streets from Google Street Map (Google, 2019), one from a zone with low sustainable mobility score and the other with a high sustainable mobility score. The photographed locations are marked approximately on the map. This figure shows emphatically that most parts of the city with low sustainable mobility scores are located in the plain of Valparaíso, except a few zones in the extreme south of Valparaíso, on the outer limits of the urban agglomeration. Furthermore, the major part of the zones with higher scores of sustainable mobility is in the hills of Valparaíso.

Table 2: Conditions to accept, reject or discard tested hypotheses

\begin{tabular}{cccc}
\hline Hypotheses & Accept & Reject & $\begin{array}{c}\text { Not a relevant test } \\
\text { (null hypotheses) }\end{array}$ \\
\hline Neo-deterministic (H1) & p-value $<0.05$ and & p-value $<0.05$ and & p-value $>0.05$ \\
& Coefficient $>0.00$ & Coefficient $<0.00$ & \\
Socio-spatial (H2) & p-value $<0.05$ and & p-value $<0.05$ and & p-value $>0.05$ \\
& Coefficient $<0.00$ & Coefficient $>0.00$ & \\
\hline
\end{tabular}


From the images in Figure 5, the differences in urban landscapes in the survey zones with lower and higher sustainable mobility scores may be noted. The one with a lower score shows a higher density of private transportation and buses (related to public transportation) and presents a more significant density of construction (vertical landscape) and a greater presence of businesses, commerce, and services. The streets located in a zone with higher sustainability score presents a more horizontal urban landscape and an absence of private or public transportation, are more residential, with citizens walking down the street.

Table 3 shows the main results of both linear regressions, using the sustainable mobility score as the dependent variable. The main indicators analysed in this stage are the $\mathrm{p}$-values and coefficients. From the p-values, it is possible to reject in both cases the possibility that the independent variables do not have any correlation with the sustainable mobility score.

Before analysing the coefficients, it is important to recollect that when slope values are normalised, the values closer to 1 means lower slopes and closer to zero is related to steeper slopes. Understanding that lower slopes represent better conditions for walking and cycling (sustainable modes), while steeper slopes can generate more difficult conditions for these sustainable modes of mobility. For the socio-spatial condition, higher average incomes are closer to 1 and lower-income are closer to zero.

Now, regarding the coefficients, it may be seen that lower gradients (slopes) have a negative correlation with sustainable mobility. That means, in the case of Valparaíso, better slope conditions for sustainable mobility have a correlation that is contrary to the expected

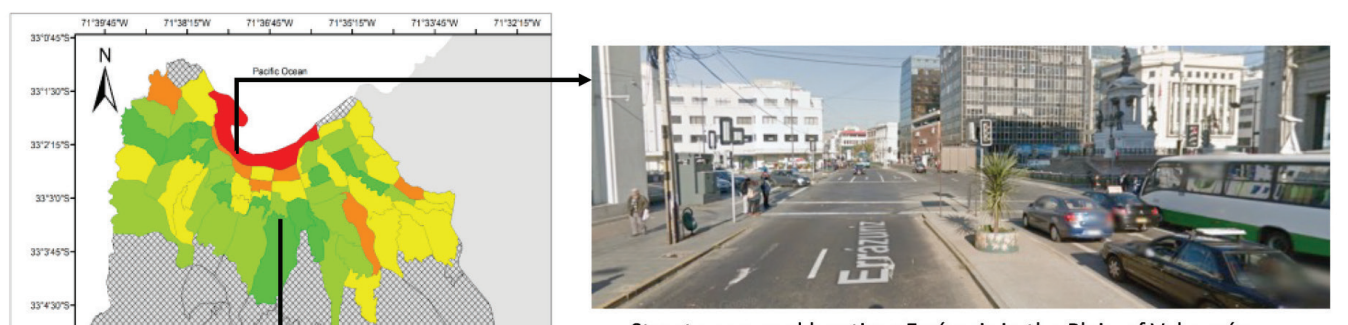

Street name and location: Errázuriz in the Plain of Valparaiso

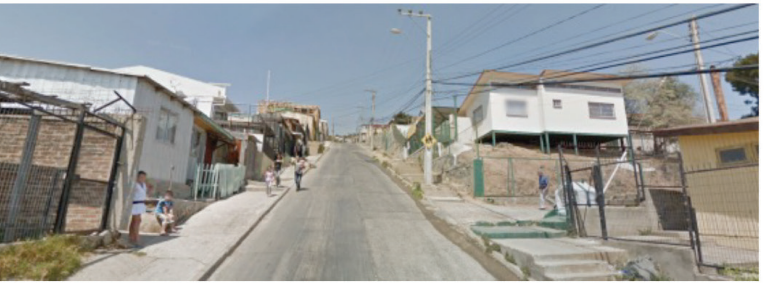

Street name and location: La Fontaine in the Cerro (Hill) La Cruz

Figure 5: Sustainable mobility score of Valparaíso with figures of streets and its approximate locations

Table 3: Results of two independent linear regressions using the sustainable mobility score as the dependent variable

\begin{tabular}{lcc}
\hline \multicolumn{1}{c}{ Independent Variables } & Coefficient & p-value \\
\hline Slope normalised & -0.81 & 0.0000047 \\
Socio-spatial condition normalised & -0.54 & 0.0175767 \\
\hline
\end{tabular}


number of walking and cycling trips, $\mathrm{CO}_{2}$ emissions, and the average travel time. Therefore, the hypothesis that gentler slopes are a conducive condition for cycling and walking and should relate to more sustainable mobility patterns is rejected. On the contrary, the result indicates that the survey zones with steeper slopes have better scores for sustainable mobility, contrary to what one might expect due to the difficult topographic conditions.

The second linear regression with the sociospatial condition shows that survey zones with higher average income indicate low scores of sustainable mobility. Therefore, lower values of average income are related to higher scores of sustainable mobility. This result proves the hypotheses presented in the introductory section of this paper, that the social inequity, interests, and contradictions lead to unsustainable mobility patterns, therefore, sustainable mobility, from a neoliberal political and economics point of view, is not a priority. This contradicts the potentiality of natural conditions of the territory as a resource to generate sustainable development and behaviour.

\section{Conclusion and Recommendations}

Overall, it is observed that a large part of Valparaíso scores high on sustainable mobility. However, analysis of the results regarding socio-spatial and topographic conditions shows glaring contradiction. Because the mobility patterns in Valparaíso are not generated by an urban environment that promotes sustainable behaviour by choice, but by socio-spatial inequality. Also, it is understood that in the Latin American context, the socio-spatial inequality in cities is closely related to the inequality of access to opportunities, amenities, and services (including transport service and infrastructure).

A part of the process, ensuring spatial justice and social equality is the responsibility of transport and urban planning authorities. Therefore, in the case of Valparaíso, results indicate that the urban development process, driven by those responsible for urban and transport planning of the city, is not inclusive in terms of promoting urban mobility with a potential to reduce social inequality, generate economic opportunities and reduce environmental impacts. There are short- and long-term implications for Valparaíso and other cities in the country that may be in a similar situation. In the short term, one could highlight the quality of life in the city and in the long term, one could point out the environmental degradation and the deepening of socio-spatial inequality. Sustainable mobility indicator read in isolation may give a false positive impression on the living conditions in a city, but when analysed in conjunction with territorial information related to human and/or physical characteristics, it is possible to discern whether positive values of indicators are a result of an adequate urban and transport planning or a chronic social inequality present in the territory. This could lead to the identification of the areas of interest of the city and generate for each area adequate sustainable mobility policies to promote a true transition towards a sustainable urban environment.

Further studies will aim to expand the number of variables that compose a sustainable mobility score, in addition to the implementation of more adequate spatial analysis methods and incorporate qualitative data related to urban and transport planning in future studies. Moreover, there is a need to research further on a smaller scales of the city, for example, at a street level, in order to understand whether the infrastructure of street spaces offer adequate and secure environments for all modes of transport (motorised and non-motorised), which deals with the understanding of the transport infrastructure from the perspective of the complete street's concept. Therefore, it should be interesting to evaluate from a spatial perspective the transport system and urban conditions of Valparaíso, aiming to measure the completeness of streets (level of safety and adequate space for users of all modes of transport) and its relationship with mobility and social patterns, understanding that the topography is not the main barrier to promote sustainable mobility in the city, but the lack of adequate urban and transport infrastructure. 


\section{Acknowledgements}

The authors extend their gratitude to reviewers for critical comments on the manuscript and the university for the research opportunity and support through the Project funding VRIEAPUCV 039.339/2021.

\section{References}

Álvarez, L., Silva, L., \& Soto, M. (2009). Dimension Espacial de la Movilidad Cotidiana Universitaria: El caso del Gran Valparaíso. Revista Invi, 24(65), 19-77.

Athens, N. C., \& Ormeño, F. V. (2010). Transformaciones en el mercado del trabajo y expresión territorial de las desigualdades sociales: el caso del área metropolitana de Valparaíso. Revista Lider, 17, 119-136.

Beheshtitabar, E., Ríos, S. A., KönigHollerwöger, D., Svatý, Z., \& Rydergren, C. (2014). Route choice modelling for bicycle trips. International Journal for Traffic and Transport Engineering, 4(2), 194-209. doi: 10.7708/ijtte.2014.4(2).06

Borsdorf, A., \& Hidalgo, R. (2008). Open Port - Closed Residential Quarters? Urban sStructural transformation in the metropolitan area of Valparaíso, Chile. Erkunde, 62(1), 1-13.

Bourne, L. S. (1976). Internal structure of the city (6 ed.). New York: Oxford University Press.

Brundland, G. (1987). Report of the World Commission on Environment and Development: Our common future. Oxford: United Nations.

Caro, M. S., \& Aránguiz, L. A. (2012). Análisis de tendencias en movilidad en el Gran Valparaíso. El caso de la movilidad laboral. Revista de Geografía Norte Grande, 52, 1936.

Castells, M. (2009). A Questao Urbana (4th ed.). Sao Paulo: Editora Paz e Terra S/A.

Cervero, R., Sarmiento, O. L., Jacoby, E., Gomez, L. F., \& Neiman, A. (2009). Influences of built environments on walking and cycling: Lessons from Bogotá. International Journal of Sustainable Transportation, 3(4), 203226. doi:10.1080/15568310802178314

CGIAR-CSI. (2018). Consortium for Spatial Information. Obtenido de SRTM $90 \mathrm{~m}$ Digital Elevation Database. http://srtm.csi. cgiar.org/SELECTION/inputCoord.asp

Coe, N. M., Kelly, P. F., \& Yeung, H. W. (2007). Economic geography: A contemporary introduction. Oxford: Blackwell.

Corrêa, R. L. (1995). O Espaco Urbano. Sao Paulo: Ática.

Dargay, J. M. (2001). The effect of income on car ownership: Evidence of asymmetry. Transportation Research Part A: Policy and Practice, 35(9), 807-821. doi: 10.1016/ S0965-8564(00)00018-5

Dargay, J. M., \& Vythoulkas, P. C. (1999). Estimation of a Dynamic Car Ownership Model: A Pseudo-Panel Approach. Journal of Transport Economics and Policy, 33(3), 287-301. Obtenido de https://www.jstor. org/stable/20053816

Fernandes, V. A. (2017). Resilience of urban mobility in the face of fossil fuel dependency: An empirical study of Rio de Janeiro. Tuebingen: Universitätsbibliothek Tübingen. doi:http://dx.doi.org/10.15496/ publikation-17153

GFEI. (2018). Cleaner, More Efficient Vehicles. Obtenido de https://www. globalfueleconomy.org/transport/gfei/ autotool/case_studies/samerica/chile/cs_ sa_chile.asp

Google. (2019). https://www.google.com/maps.

Guikink, D. (2019). Sustainable Urban Mobility Practices. Eltis - The urban mobility observatory (págs. 1-19). Eltis. Obtenido de Eltis - The urban mobility laboratory: http:// www.eltis.org/sites/default/files/events/ documents/04. seminar sustainable urban_mobility_don_guikink.pdf 
Hanson, S., \& Giuliano, G. (2004). The geography of urban transportation. New York: Guilford Press.

Henriquez, C., Azocar, G., \& Romero, H. (2006). Monitoring and modeling the urban growth of two mid-sized Chilean cities. Habitat International, 30, 945-964.

IBGE. (2010). Censo Demográfico 2010: Aglomerados Subnormais. Instituto Brasileiro de Geografia e Estatistica. Obtenido de http://biblioteca.ibge.gov. br/visualizacao/periodicos/552/cd_2010_ agsn_if.pdf

Jenks, F. G. (1967). The data model concept in statistical mapping. International Yearbook of Cartography, 7, 186-190.

Judkins, G., Smith, M., \& Keys, E. (2008). Determinism within human-environment research and the rediscovery of environmental causation. The Geographical Journal, 174(1), 17-29. doi: 10.1111/j.14754959.2008.00265.x

Lin, J.-J., \& Chang, H.-T. (2009). Built environment effects on children's school travel in Taipai: Independence and travel mode. Urban Studies, 47(4), 867-889. doi: 10.1177/0042098009351938

Litman, T. (2007). Developing indicators for comprehensive and sustainable transport planning. Journal of the Transportation Research Board, 2017, 10-15. doi:10.3141/2017-02

Meyer, W. B., \& Guss, D. M. (2017). Neoenvironmental determinism. En W. B. Meyer, \& D. M. Guss, Neo-environmental determinism (págs. 39-96). Cham: Palgrave Macmillan. doi:10.1007/978-3-319-542324_5

Olivi, A., Fadda, G., \& Reyes, V. (2016). Movilidad urbana y calidad de vida de las personas mayores en una ciudad vertical. El caso de Valparaíso, Chile. Revista Márgenes, 13(19), 38-47.

Paniagua, Á., \& Moyano, E. (1998). Medio ambiente, desarrollo sostenible y escalas de sustentabilidad. Reis: Revista Española de Investigaciones Sociológicas, 151-175. doi: $10.2307 / 40184124$

Rodrigue, J. P., Comtois, C., \& Slack, B. (2013). The geography of transport systems. New York: Routledge.

Rogerson, P. A. (2012). Métodos Estatísticos para Geografia: Um Guia para Estudante (3rd ed.). Porto Alegre: Bookman.

Rojas, C., Páez, A., Barbosa, O., \& Carrasco, J. (2016). Accessibility to urban green spaces in Chilean cities using adaptive thresholds. Journal of Transport Geography, 57, 227240.

Sánchez, A., Bosque, J., \& Jimenéz, C. (2009). Valparaíso: su geografía, su historia y su identidad como Patrimonio de la Humanidad. Estudios Geográficos, 70(266), 269-293. doi:10.3989/estgeogr.0445

Su, J. G., Winters, M., Nunes, M., \& Brauer, M. (2010). Designing a route planner to facilitate and promote cycling in Metro Vancouver, Canada. Transportation Research Part A: Policy and Practice, 44(7), 495-505. doi:10.1016/j.tra.2010.03.015

Subsecretaría de Transporte. (2014). Subsecretaría de Transporte. Obtenido de Encuesta de Origen y Destino de Viajes del Gran Valparaíso 2014: http://datos.gob.cl/ dataset/eod-valpo-2014

UN. (2016). Mobilizing Sustainable Transport for Development. New York: United Nation. Obtenido de https:// sustainabledevelopment.un.org/content/ documents/2375Mobilizing\%20Sustainable \%20Transport.pdf

UNDP. (2018). Sustainable Development Goals. Obtenido de United Nations Development Programme: http://www.undp.org/content/ undp/en/home/sustainable-developmentgoals.html

UNESCO. (2003). Historic Quarter of the Seaport City of Valparaíso. Obtenido de https://whc.unesco.org/en/list/959 
United Nations. (2017). Chile: Taking Action for Sustainable Development. New York: United Nations. Obtenido de https:// www.un.org/sustainabledevelopment/ wp-content/uploads/2017/07/Chile_ Government.pdf

Ureta, S. (2008). To move or not to move? Social exclusion, accessibility and daily mobility among the low income population in Santiago, Chile. Mobilities, 3(2), 269289.

Urquieta, C. Q. (2018). Moldeando prácticas y hábitat: estrategias de movilidad cotidiana en cerros de Valparaíso. Universitas humanística, (85), 125-151.
Vasconcellos, E. A. (2014). Urban transport environment and equity: The case for developing countries (1st ed.). London: Routledge. doi:Urban Transport Environment and Equity: The case for developing countries.

Zegras, P. C. (2004). Influence of land use on travel behavior in Santiago, Chile. Transportation Research Record: Journal of the Transportation Research Board (1898), 175-182.

Zegras, P. C., \& Srinivasan, S. (2007). Household income, travel behavior, location, and accessibility. Transportation Research Record: Journal of the Transportation Research Board, (2038), 128-138. 